\title{
The Causes, Problems and Countermeasures of Super Network Platform
}

\author{
Ye Xiumin ${ }^{1}$, Fang Xingdong ${ }^{2}$ \\ ${ }^{1}$ Institute of Quantitative Economy and Technological Economy, Chinese Academy of Social Sciences, Beijing, China \\ ${ }^{2}$ Internet and Social Research Centre, Zhejiang Media College, Beijing, China
}

Email address:

xmye@cass.org.cn (Ye Xiumin), fxd@chinalabs.com (Fang Xingdong)

To cite this article:

Ye Xiumin, Fang Xingdong. The Causes, Problems and Countermeasures of Super Network Platform. Science Journal of Business and Management. Vol. 8, No. 2, 2020, pp. 90-95. doi: 10.11648/j.sjbm.20200802.16

Received: February 12, 2020; Accepted: May 12, 2020; Published: May 27, 2020

\begin{abstract}
Super network platform is the product of the development of the times, together with the drive of modern information technology, market competition and capital. Super network platform plays an increasingly important role in economic and social life. Super network platform is an important part of the digital economy. It not only becomes a new business form, but also drives the transformation and upgrading of traditional manufacturing industry, and promotes employment and entrepreneurship, and changes people's way of life, work and learning. However, part of the rights and responsibilities of the super network platform have gone beyond the scope of the enterprise. The platform has become the direct manager of hundreds of millions of users, has infrastructure resources related to national economy and people's livelihood, and has the initiative of media discourse. If we let bad behavior go unchecked, it will bring many threats to consumer rights, fair competition of business, government governance and national security. Governance of super network platform is a new complex problem faced by all countries in the world. We need to stand at a higher angle, balance the relationship between development and governance, take an inclusive and prudent attitude, crack down on unfair competition, prevent and reduce system security risks, and give full play to the value of super network platform.
\end{abstract}

Keywords: Super Network Platform, Bilateral Market, Platform Economy, Monopolistic Competition

\section{Introduction}

Since the birth of the Internet, China's network economy has achieved rapid development [1], overtaking in the curve, and becoming a catalyst to promote the development of the entire economic transformation [2] [3]. In the future, driven by modern information technologies such as $5 \mathrm{G}$ and blockchain, the Internet will continue to be a new driving force for innovation and development at all levels of China's economy and society, as well as a main battlefield for building global soft power. Therefore, the Internet industry must maintain healthy and sustainable innovation vitality. This is not only related to the healthy growth of the Internet industry, but also related to the overall healthy development of China's economy and society [4]. In the whole industrial chain of the Internet, the Internet platform has become a key subject, which has penetrated all fields of the economy and society. Especially in recent years, super network platform is the focus of attention [5]. Super network platform refers to a network platform with 1 billion active users, high stickiness to users, important information infrastructure, strong mobilization ability and industrial dominance, and continuous expansion [6].

However, with the increasing influence of super network platforms, some of their competition behaviors begin to step on the red line, even break the legal bottom line from time to time, resulting in vicious competition and abuse of market dominance, which has brought a lot of negative effects in the industry and caused widespread concern of the society [7]. According to all kinds of research results and long-term observation of industry monopoly, it can be found that when an industry's monopoly behavior is not regulated, it will have a far-reaching negative impact on its own innovation, industry development, consumer rights and social progress [8]. This is also one of the important reasons that countries all over the world are always on high alert to the monopoly behavior of enterprises [9]. In view of this, in order to better promote the long-term development of China's Internet industry, this paper studies the behavior of Internet industry super network 
platform, and puts forward targeted countermeasures and suggestions. It is hoped that the government will pay attention to the monopoly and harm of the Internet industry, promote the healthy development of the Internet industry, and give more small and medium-sized enterprises opportunities for innovation and development.

\section{The Causes for the Formation of Super Network Platform}

\subsection{The Platform Is a Bilateral Market}

Take online retail platform as an example, the platform is divided into open platform and closed platform. Open platform refers to the open platform interface, which allows other businesses (also known as online merchants or online shopkeepers) to use platform resources to sell products and provide services for consumers. For example, Taobao, Mall, PinDuoDuo, JingDong (except for its own business) are all open platforms. The open platform provides support services. The platform itself does not sell products. Products and services are completed by the third-party merchants. All the platforms mentioned in this paper refer to the open platform.

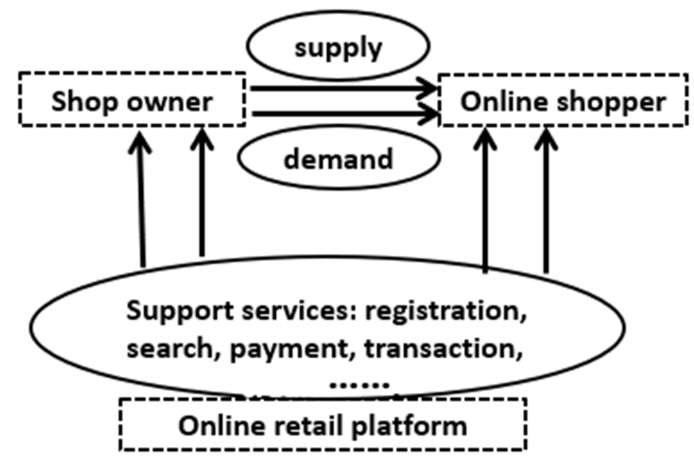

Figure 1. Composition of online retail platform.

Online retail platform is a bilateral market, with two or more independent user groups, among which the most basic two users are online business group and online shopping group [10]. Platforms, online merchants and online shoppers are symbiotic, win-win and interdependent. Merchants can open stores on the platform, display commodities, carry out publicity and promotion, sell commodities to online shoppers, and meet the needs of consumers. Shoppers search for more interested commodity information with the help of basic services provided by the platform, and then buy the desired commodities. The basic services provided by the platform are usually free. Platform revenue comes from value-added services such as advertising and competitive ranking.

\subsection{Platform Economy Has "Network Externality"}

Online platform has "network externality", the scale of one type of users will significantly affect the utility or value of another type of users. Take Taobao platform as an example, the more the number of online shopkeepers, the richer the goods they provide, the more fierce the competition of similar products, the lower the price, and the greater the attraction and value to online shopping users. Similarly, the more online shopping users on the platform, the stronger the purchasing power, and the greater the attraction to online shopkeepers. The two kinds of users on the platform influence and promote each other, forming a unique network externality. Economist WuJinglian summed up this characteristic of platform economy as "positive feedback". He thought that "from the perspective of economics, one of the characteristics of platform economy is that scale forms a positive feedback state. Moreover, there is not only the scale economy of the producer, but also the scale economy of the consumer. The larger the scale is, the more effective the scale is, the larger the effective scale becomes, and finally a high market share may be formed, involving the monopoly in the economic sense. "

Table 1. Penetration rate of mobile e-commerce app (December 2017).

\begin{tabular}{lll}
\hline mobile e-commerce app & Penetration rate & Penetration growth rate \\
\hline Mobile Taobao & $53.40 \%$ & $7.70 \%$ \\
Mobile Jingdong & $20.70 \%$ & $33.80 \%$ \\
Pinduoduo & $19.00 \%$ & $1507.60 \%$ \\
Vipshop & $15.67 \%$ & $22.40 \%$ \\
Tmall & $7.97 \%$ & $-9.20 \%$ \\
\hline
\end{tabular}

(source: Aurora big data)

\subsection{Features Drive the Platform Scale Growth}

The features of the platform lead to the continuous expansion of the number of multi-party users, more and more, showing the trend of large-scale development, which is also known as clustering, clustering or "Matthew effect" [11]. The two users of the online platform have a positive impact, promote each other, and promote explosive growth until the formation of a large-scale online shopping platform. The practice field also verified the scale trend of the comprehensive online retail platform. According to the financial report, the number of active users of JD in 2018 increased by $4.38 \%$ to 305 million. Alibaba's data shows that the annual active consumers of its Chinese platform reached 552 million, up 7.18\% year on year. According to Amazon's seller report, in 2018, there were 310 million active buyer accounts in 14 sites around the world, and the number of sellers grew rapidly. In the first 11 months of 2018, there were 1 million new sellers, which means that about 3000 sellers joined Amazon platform to sell products every day.

\subsection{The Game Rules of the Internet Industry Also Drive the Platform Scale Growth}

Different from the competition rules in the traditional field, the start-up platform enterprises usually have no profit in the early stage of development and rely on venture capital to maintain operation. Venture capital usually favors the top companies in each industry segment, because only these companies are likely to survive in high competition, and more likely to cash out through multiple rounds of financing or IPO. Therefore, at the beginning of platform entrepreneurship, it is 
one of the most important tasks for platform enterprises to quickly increase the number of users. The most effective way for the platform to attract users is free, large-scale subsidies or various promotional activities. Once users form scale, the platform can absorb all kinds of venture capital. With capital, the platform can invest more money in technology research and development, business innovation and marketing activities. When users form a certain scale and have a certain degree of loyalty, they can provide all kinds of value-added services and gradually get income and profits.

\subsection{Scale Promotes the Platform to Gain Market Advantage}

Once the user scale gains the advantage, the platform will accumulate this advantage, obtain more customers, funds, talents, policies and other resources, and then make more opportunities and progress. This positive cycle continues to enhance the influence of the platform until it forms an absolute leading position. There are significant differences between the competition rules of the Internet and the traditional market. If the platform enterprises want to gain the competitive advantage, they must grow rapidly in this field. Horse racing, land enclosure and money burning are usually necessary business links in the early stage. Once the platform become the market leader, it will gain more resource support, including funds, policies and talents. The platform has sufficient strength to continue to grow or expand to other fields with more resources.

Due to the continuous aggregation of multiple users, the online retail platform gradually forms many users, and the volume of transactions continues to enlarge. Therefore, the platform will also have a higher market share in the segment market. In China's mobile online shopping market, the market share of Taobao + Tmall is $85.6 \%$, with absolute market advantage. In China's mobile social field, Wechat has 1.058 billion monthly active users with no competitor.

\section{Super Network Platform Is Growing Into an Economy That Can Play with the Government}

The super network platform represented by Alibaba, etc. is internalizing into an economy that can form a game with the government with the network effect as the attraction, capital invasion as the means, and public opinion control as the guidance by using the position of the platform and the power of capital [12].

\subsection{Super Network Platform Gathers Hundreds of Millions of Users and Becomes the Direct Manager of Cyberspace}

The characteristics of network externality and winner taking all of super network platform are more obvious. For example, the number of users of Taobao, Tmall, Ant-Financial and other platforms under Alibaba platform is up to hundreds of millions; the number of Wechat and QQ users under
Tencent platform is close to one billion. The number of users managed by the super network platform can almost surpass the total population of any other country and become a new economy with organizational attributes in cyberspace.

Users in cyberspace are like individuals in real society, whose behavior rules are restricted by platform rules. Due to the lack of network platform management in current policies, each super network platform has independently undertaken various management work of network space. From formulating various rules of the platform to identifying and punishing platform violations, they have become the direct managers of network space [13]. With the stability of the position of power and responsibility which integrates public power and private rights, the super network platform may hinder the government to further promote the governance of cyberspace.

In addition, the influence of network platform in the economic field cannot be ignored. In 2016, the total transaction volume of Alibaba exceeded US \$500 billion. Ma Yun declared that Alibaba has already surpassed a company and is an economy, and will become the fifth largest economy in the world after the United States, China, Europe and Japan in 2036 in his speech at Alibaba's 18th anniversary annual meeting.

\subsection{Invest Heavily in All Kinds of Media Resources and Grasp the Initiative of Media Discourse}

Strengthening the media discourse power is an important way to enhance the influence of super network platform. In order to prevent the influence of the platform from being controlled by the market and actively influence the market, super network platform has found a shortcut to invest media resources. It is reported that Ali has invested heavily in more than 20 media enterprises and platforms. Tencent is also known as China's largest new media company.

At present, China's media industry has basically formed a tripartite confrontation. Official media with government resources as the background and social media represented by Ali department and Tencent department respectively. As an important transmission channel of the government voice, the official media carries the important social mobilization function. Alibaba and Tencent's own media resources carry their own interests and influence, which influence public opinion and weaken the adverse information to the enterprise. Compared with the seriousness of the official media, their entertainment can cater to the audience better, which is an important force in the social propaganda system.

\subsection{Positioning Infrastructure Resources Related to National Economy and People's Livelihood, and Enhancing the Power of Game}

MaYun once said that in the future, the services provided by Alibaba will be the fourth indispensable business infrastructure resources beyond the water, electricity and land. Water, electricity and land are all national control resources related to national economy and people's livelihood, but the 
data resources in cyberspace are "new renewable resources" ignored by the state. With its overwhelming wealth gathering effect and unstoppable competitive advantage, as well as strong social mobilization ability and massive data gathering ability, super network platform has gradually become an indispensable new infrastructure for people in cyberspace. The government, which dominates the core infrastructure in the real space, is in an awkward position of being absent in the cyberspace.

Because of the lack of government's efficiency in cyberspace, the network super platform has become the provider of public goods such as infrastructure and system construction to a large extent. It will bring new game to government governance in the era of cyberspace for the non-governmental forces to provide infrastructure functions and services beyond the responsibilities of the government [14].

\section{Super Network Platform Will Bring New Threats to Government Governance and National Security}

The "super" of the super network platform is not only because it has a large number of users, a large amount of money, influences the market, and influences public opinion, but also because it has a great impact on the instability of national security.

\subsection{Vie Structure Brings Instability of Platform Control and Outflow of Wealth}

There are vie structure problems in domestic super network platforms, which have not been effectively solved, which has become an important threat to China's Internet development and even national economic and political security [15].

Although Alibaba and Tencent achieved daily management of the company with the founder as the representative through agreement, this was the result of temporary compromise between the two sides. The original expediency became a real instability. Alibaba's high valuation, which is listed in the us with vie structure, is based on the development of domestic value-added business. With the value of domestic users, government support and social resources, Ali has left its wealth abroad, which is another phenomenon of wealth outflow. In addition, Alibaba needs to follow the information disclosure system of the American exchange. Any disclosure of directional information means that it is possible to be used. The outflow of specific business information will bring risks to China's economic and political security [16].

\subsection{Data Monopoly Threatens National Network Security}

Data governance will be the most fundamental governance in cyberspace. The most valuable thing of Alibaba platform is the massive data, which will also be the main contradiction between super network platform and national interests in the future.

The importance of data has been paid more and more attention. The transaction system based on e-commerce and payment established by Alibaba platform has obtained massive data of users. Many real data maps can be obtained by processing and interpreting these data. Ma Yun once said that Alibaba's economic development measured by using platform data is even more accurate than that of the national statistical department, and can even show the reality half a year in advance.

If the massive transaction data and financial data on the platform are improperly used, it will not only infringe the rights and interests of consumers, but also bring risks to the national financial security, and even damage the national security. Alibaba can develop and use data resources, but super network platform can't damage national security interests for commercial interests, which can't be recovered once it happens.

\subsection{The "Two Governments" with Public Attribute Arrogate the Function of Government Governance}

The super network platform integrates public rights and private rights, integrates daily network supervision, content review, users' information protection and various services, formulates and implements most network governance rules, and becomes the "two governments" of cyberspace facts, which is too powerful to shake.

Super network platform can directly affect the vital interests of each netizen, and has obvious publicity. However, the public orientation of the super network platform is lack of clear norms, public policies are not formed, and each code of conduct is determined by the interests and preferences of the super network platform. The functions of government agencies in cyberspace are increasingly ignored. In the traditional sense, the important function of the government is to build and control strong infrastructure, provide public services based on the maximization of social interests, and also to formulate and maintain laws and systems. It can be seen that with the growing strength of the super network platform, the role the government plays in the governance of the network platform will surely rewrite the key functions and legitimacy of the government in the future.

\subsection{The Disordered Competition of the Platform Is Exposed from Time to Time}

Recently, a series of disputes between platforms in the field of e-commerce show that the order of platform competition needs to be further improved. In the "618" online shopping promotion in 2017. Media reports showed that in the face of "two choices one", TaoBao brand "QiGeGe" and "LieBo" announced their withdrawal from Jingdong. In the "double 11" of 2017 , it also revealed that the platform requires businesses to only promote on their own platform, and forces businesses to sign an "exclusive cooperation agreement" with them to ensure that products are only sold on the platform, and to close stores on other platforms. In June 2017, Cainiao and Shunfeng company interrupted their data connection due to the problem of opening the user information interface, resulting in the user 
unable to query the logistics information and affecting the consumer experience. In April 2018, Didi travel launched its takeout business in Wuxi. However, some businesses in the park said that the service port was stopped by Meituan's comments on takeout due to its participation in DiDi takeout. The outbreak of a series of irrational competition shows that in the increasingly severe competition environment, platform enterprises do not abide by the market rules and conduct irrational blind competition in order to obtain their own private interests.

The disordered competition of e-commerce platform is very harmful. One is to destroy the market competition order and disturb the fair competition market environment. Second, it damages the free choice right of merchants, hinders the merchants to expand the market, makes the business more and more difficult to do, and weakens the fair right of merchants to obtain more customers and business opportunities. Third, disordered competition also damages the interests of consumers and reduces their shopping experience. Fourth, blind competition is against the original intention and vision of the enterprise, short-sighted and selfish behavior is not conducive to the long-term development of the enterprise.

\section{Pay Attention to and Deal with the Problems of Super Network Platform Governance, and Prevent System Security Risks}

The governance of super network platform is a new complex problem faced by all countries in the world. It is necessary to stand in a higher angle, balance the overall development and governance, grasp the gap period before the formation of the risk of super network platform as early as possible, make scientific arrangement and research, give play to the multi-level wisdom of the government and society, and prevent and reduce the risk of system security.

\subsection{Adhere to an Inclusive and Prudent Attitude and Improve the Awareness of Necessary Risks}

"As soon as it is released, it will be disordered, and as soon as it is managed, it will be stiff " reflects the difficulty of the government in the face of development and management. China's Internet industry as a whole has enjoyed the dividend of the policy, and the rapid growth of China's Internet market has also given a better answer to the policy. China's super network platform represents the international competitiveness of the domestic Internet industry has reached a high level. Super network platform is a new thing, it has the value and necessity of existence, but also has visible and invisible risks. Governance should not underestimate the stability, influence and potential of the platform.

Adhering to an inclusive and prudent attitude can enable the super network platform to continue to play its value in promoting economic transformation and upgrading and in participating in international competition in the image of
China. The necessary risk awareness is to investigate the potential hazards of the super network platform, find out the risk coefficient points and deduce the response methods, so as to achieve free response.

\subsection{After Full Investigation, Put on the Brake for a Series of Behaviors of Super Network Platform}

The system risk of super network platform is found by the investigation, and some behaviors that have already generated risks but cannot be restricted by law are put on the brake as soon as possible.

The vie structure of the super network platform, the problem of capita restraining innovation, the problem of "two governments" governance that data monopoly endangers national security risks, etc., are not all kinds of risks according to the research of the existing public information. As a public authority, the government has more authority and more channels to investigate the risks of super network platform, and to step on the brakes as soon as possible on the monopoly and merger problems that have appeared. The current situation of Taxi APP market has shown the negative effects of government regulators' untimely identification and handling of monopoly behaviors. Holding on to the hot issues and stepping on the brake can establish a demonstration effect, so that the development of super network platform will gradually return to the normal track, rather than constantly moving towards the other side of things in the expansion.

\subsection{Explore the Logical Governance in Line with the Hander Formula, and Let the Management Have a Grasp}

The governance of super network platform needs to explore the governance mode that conforms to the multi-level and multi center rules. By guiding the third party with independent attributes to participate in the platform governance, the game between the government and the platform can be alleviated and the role of coordination and co-governance can be better played. The non-fixed and non-lifetime system of the third party can also enhance the fairness and justice of the platform governance.

In order to achieve good results, scientific test criteria and follow-up processing mechanism are needed. Hander formula meets the above requirements. The Hander formula, originated from the United States, is a widely referenced principle of responsibility sharing: that is, the responsibilities of all parties involved in the accident are inversely proportional to the costs they need to pay to avoid the accident, that is, the easier it is to avoid the accident, the greater the responsibility it bears. Therefore, a set of governance standard system with self-checking and self-correcting function should be established, so that the relevant policies can adapt to the rapid development of the Internet in the future while managing the super network platform. 


\subsection{Platform Enterprises Establish a Sense of Social Responsibility}

In pursuit of economic benefits, enterprises should never neglect their sense of social responsibility. First, enterprises should strengthen the awareness of social enterprises, establish a sense of responsibility, integrate the interests of enterprises into the common interests of the development of the whole society, and significantly enhance the pride and self-confidence of employees. Second, enterprises should abandon selfish and short-sighted behavior, and integrate social responsibility into the corporate vision and development strategy. Only in this way can the enterprise flourish forever. Third, while operating in good faith, the enterprise shall perform necessary social responsibilities and obligations, provide satisfactory services for users, compete fairly, participate in public welfare activities, and realize the coordinated development of the enterprise and the environment. Fourth, we will integrate the sense of social responsibility into the corporate culture, enhance the education and training of employees, enhance the pride and self-confidence of employees, and encourage the enthusiasm of employees.

\section{References}

[1] Ali Research Institute, platform economy, social sciences literature press, may 2016.

[2] Ye Xiumin, research on e-commerce ecosystem, social sciences literature press, November 2010.

[3] Xu Jin, platform economy, Shanghai Jiaotong University Press, July 2013.

[4] Chen Qinghe, Wang Zhipeng, Tu Jingyi and Zhang Xiangjian: power generation and power structure analysis of platform organization, Journal of Graduate School of Chinese Academy of Social Sciences, No. 2, 2016.

[5] Ye Xiumin: analysis of the characteristics of platform economy, Journal of Hebei Normal University (PHILOSOPHY AND SOCIAL SCIENCES EDITION), 2016, issue 2 .

[6] FangXingdong, Yan Feng: the formation and governance of "super power" of network platform, people's forum, academic frontier, July 2019Tan Ruicong: platform economy and science and technology resource sharing, East China Science and technology, 2012, Issue 9.

[7] Massimo Mota. Competition policy: Theory and practice [M]. Shanghai University of Finance and Economics Press, 2006: 307.

[8] XueHong: on the third-party transaction platform of E-commerce -- the trio of power, responsibility and accountability, Journal of Shanghai Normal University (PHILOSOPHY AND SOCIAL SCIENCES EDITION), issue $5,2014$.

[9] Bao Ximei. Economic analysis of antitrust law [M]. Beijing: China Social Sciences Press, 2003: 77.

[10] Zhang Xiaoyuan, Cao niangeng, a review of the research on bilateral market theory platform economy, Journal of Shandong University of administration, February 2013.

[11] Mei Xiaying, Yang Xiaona: the formation and normative path of the network power of the self media platform -- Based on the freedom of speech on the network Impact analysis, Hebei law, 2017, issue 1 .

[12] Sun Guoqiang, Zhang Baojian, Xu Lifeng: a review and Prospect of the theoretical research of network power, foreign economy and management 8 . Li, 2014, issue 12 .

[13] Li Sanhu: technology, space and power: Michelle Foucault's philosophy of technology politics, public management 10 . Journal, 2006, issue 3.

[14] Song Hongyan: the generation, conflict and morality of network power, Jianghuai forum, 2013, issue 3.

[15] Yan Feng, Formation and governance of "super power" on network platform, people's forum, academic frontier, July 2019.

[16] Andersson S chwarz, J. "Mastering One's Domain: Some Key Principles of Platform Capitalism", 2016. 